\title{
The effect of cognitive task on postural stability in cervical dystonia
}

\author{
O efeito da tarefa cognitiva sobre a estabilidade postural na distonia cervical \\ Turgay DEMIR1, Mehmet BALAL ${ }^{1,2}$, Meltem DEMIRKIRAN ${ }^{1,2}$
}

\begin{abstract}
Background: Cervical dystonia (CD) is the most common form of focal dystonia. It is not known exactly whether abnormal head postures in cervical dystonia cause balance problems. Dual-tasking is a common every-day life situation. Objective: We aimed to evaluate postural stability (PS) in patients with CD and the effect of cognitive task on PS. As a secondary aim, we evaluated the effect of onabotulinum toxin A (BoNT) injection on PS. Methods: A total of 24 patients with CD who were on BoNT treatment for at least one year and 23 healthy controls were included. Posturographic analyses were carried out in all the subjects on static posturography platform under four different conditions: eyes open, eyes closed, tandem stance and cognitive task. In patients, posturographic analysis was carried out just before the BoNT injections and was repeated four weeks later. Results: Before treatment, the anterior-posterior sway was significantly higher in CD patients with the eyes open condition compared to the controls $(p=0.03$ ). Cognitive task significantly affected several sway velocities. Tandem stance significantly affected many sway parameters, whereas the eyes closed condition did not. After treatment, only two parameters in tandem stance and one in cognitive task improved within the patient group, in a pairwise comparison. Conclusions: Postural control is impaired in CD patients probably due to the impaired proprioceptive and sensorimotor integration. In reference to dual task theories possibly due to divided attention and task prioritization, cognitive dual-task and harder postural task disturbes the PS in these patients.
\end{abstract}

Keywords: Botulinum Toxin; Torticollis; Cognition; Posture; Postural Balance.

\section{RESUMO}

Introdução: A distonia cervical (DC) é a forma mais comum de distonia focal. Não se sabe exatamente se posturas anormais da cabeça na DC causam problemas de equilíbrio. A execução de duas tarefas simultaneamente é situação comum da vida cotidiana. Objetivo: Avaliar a estabilidade postural (EP) em pacientes com DC e o efeito da tarefa cognitiva na EP. Como objetivo secundário, avaliamos o efeito da toxina onabotulínica A (BoNT) na EP. Métodos: Foram incluídos 24 pacientes com DC em tratamento com BoNT por pelo menos um ano e 23 controles saudáveis. As análises posturográficas foram realizadas em todos os sujeitos na plataforma de posturografia estática sob quatro condições diferentes: olhos abertos, olhos fechados, postura tandem e tarefa cognitiva. Nos pacientes, a análise posturográfica foi realizada imediatamente antes das injeções de BoNT e após quatro semanas. Resultados: Antes do tratamento, a oscilação ânteroposterior era significativamente maior nos pacientes com DC com os olhos abertos quando comparados aos controles ( $p=0,03$ ). A tarefa cognitiva interferiu significativamente nas velocidades de oscilação. A postura tandem afetou significativamente muitos parâmetros de oscilação, enquanto a condição de olhos fechados não. Após o tratamento, apenas dois parâmetros na posição tandem e um na tarefa cognitiva melhoraram no grupo de pacientes. Conclusões: O controle postural é prejudicado em pacientes com DC, provavelmente devido à comprometida integração proprioceptiva e sensório-motora. Em referência às teorias de dupla-tarefa, possivelmente devido à atenção dividida e à priorização de tarefas, a dupla-tarefa cognitiva e a tarefa postural mais difíceis perturbam o EP nesses pacientes.

Palavras-chave: Toxinas Botulínicas; Torcicolo; Cognição; Postura; Equilíbrio Postural.

\section{INTRODUCTION}

Cervical dystonia $(\mathrm{CD})$ is the most common form of focal dystonia. Its prevelance ranges from 20-4,100 cases/million¹.
It causes involuntary contraction of neck muscles, leading to tonic or clonic head movements, subsequently resulting in sustained abnormal head postures. It has several types: torticollis, laterocollis, anterocollis and retrocollis. Most patients

${ }^{1}$ Çukurova University, Faculty of Medicine, Department of Neurology, Adana, Turkey.

${ }^{2}$ Çukurova University, Faculty of Medicine, Movement Disorders Unit, Department of Neurology, Adana, Turkey.

Turgay DEMiR (iD https://orcid.org/0000-0002-7076-8571; Mehmet BALAL (iD https://orcid.org/0000-0001-8320-6597;

Meltem DEMIRKIRAN (D) https://orcid.org/0000-0002-4649-5315

Correspondence:Turgay Demir; E-mails:drtdemir@gmail.com, tdemir@cu.edu.tr

Conflict of interest: There is no conflict of interest to declare.

Ethical approval: Cukurova University, Faculty of Medicine Ethics Committee approved the study protocol (protocol number: 78-2016.06.01_32).

Informed consent: Informed consent was obtained from all participants included in the study.

Received on September 21, 2019; Received in its final form on November 29, 2019; Accepted on March $24,2020$. 
with $\mathrm{CD}$ have mixed type postures ${ }^{2}$. In addition to abnormal postures, some patients have clonic head movements resulting in dystonic tremor. Botulinum toxin (BoNT) treatment is the first line treatment for $\mathrm{CD}$ and is reported to be effective in $70-92 \%$ of patient ${ }^{3,4}$. Whether abnormal head posture cause balance problems in $\mathrm{CD}$ is unknown.

Postural control and balance are provided by somatosensory integrations as well as the integration of vestibular and visual inputs 5 . In $\mathrm{CD}$, sensorimotor integration deficits detected by motor-evoked potentials with transcranial stimulation have been reported ${ }^{6}$. It is emphasized that sensorimotor integration deficits seen in these patients are related to impaired neck proprioception, and impaired neck proprioception leads to balance and posture impairments ${ }^{7,8,9,10,11}$. Mild deficits in vestibular reflexes have been defined in patients with $\mathrm{CD}^{12}$. The vestibular system has complex connections within the brain stem, thalamus and cortex. In CD, it is possible that there is a defect in these central connections and in their relation with other modalities that control head and eye movements in particular ${ }^{13}$. However, studies have controversial results on this subject ${ }^{13,14,15,16,17}$.

There are some studies on postural balance in CD. Barr et al. compared the functional measures of mobility, gait, reaction time, and postural balance in ten people with $\mathrm{CD}$ and ten healthy controls. They reported that CD patient swayed more than controls, with poor postural control ${ }^{18}$. De Pauw et al. compared postural control during quiet sitting in 23 patients with $\mathrm{CD}$ and 36 healthy controls. They reported increased postural sway and impaired PS in CD patients. Bove et al. studied PS in $16 \mathrm{CD}$ patients and 12 healthy controls, CD patients were found to sway definitely more than controls ${ }^{7}$. Lekhel et al..$^{19}$ and Moreu et al. ${ }^{20}$ reported no differences in postural sway in stance between healthy controls and patients with $\mathrm{CD}$. These studies all have different methodological approaches and the results were controversial.

Dual-tasking, a common every-day life situation, is the ability to coordinate performance on two functional activity performing simultaneously ${ }^{21}$. During daily activities, humans involuntarily perform dual tasks without any problem. Daily activities, such as listening to music while walking or running, writing while listening or answering questions, are examples of dual-tasking. Healthy people can provide postural control while performing another motor or cognitive task ${ }^{22}$. There are no studies in literature evaluating the PS under dual task condition in CD patients. Furthermore, to the best of our knowledge, there is only one study on the effect of BoNT treatment on PS in these patients. Müller et al. reported no beneficial effects of BoNT on dynamic balance in phasic $\mathrm{CD}^{23}$.

Considering the currently available data from the literature, we hypothesized that CD patients may have postural instability due to abnormal head and neck postures and a cognitive dual-task may affect PS in these patients. In this sense, the primary aim of our study was to evaluate the effect of cognitive task on PS in patients with $\mathrm{CD}$. We also seek to analyze whether BoNT has any effect on the PS of these patients. Therefore, our secondary aim was to evaluate the effect of BoNT on PS, within the patient group.

\section{METHODS}

\section{Subjects}

Twenty-four patients with $\mathrm{CD}$ who were followed-up for at least one year in our movement disorders unit were enrolled in this prospective study. Inclusion criteria required patients having received BoNT injection every three months regularly for at least one year. Patients on any other treament for CD, with mental retardation or dementia, with comorbid neurological disorders that may affect posture and balance, such as polyneuropathy, ataxia, cerebrovascular disease, multiple sclerosis, rheumatologic or orthopedic problems, vestibulopathy or otological disease, severely blurred vision, on sedative drugs or substances were excluded. Written informed consent was obtained from all participants before enrollment. This study was approved by the Ethics Committee of Çukurova University, Faculty of Medicine.

Furthermore, 23 healthy controls were included. The patients and the controls were similar in age and gender distribution. Neurological examination was performed in all subjects. Except for dystonia, CD patients were neurologically normal. Dystonia severity was assessed with the Toronto Western Spasmodic Torticollis Rating Scale (TWSTRS); dystonia severity, disability and pain scores were determined ${ }^{24}$. The presence of dystonic head tremor was noted. Patients received BoNT injections as needed. All of them received onabotulinumtoxin A (BOTOX', Allergan, Inc., Irvine, CA, USA), and the muscles to be treated were selected based on the neurological examination and electromyography (EMG), according to each patient's needs. Evaluations of patients including TWSTRS and static posturographyic measurements were repeated four weeks after the injection, which is when the highest treatment effect is expected ${ }^{25}$.

\section{Posturography protocol}

Patients and controls underwent static posturography (SPG). SPG was carried out just before a new injection of BoNT in CD and was repeated four weeks later in these patients. It was performed on a force platform (Lucerne II, Otopront $^{\circ}$, Germany) in a quiet room. The subjects were told to stand on the platform in an upright position as stable as possible, barefoot, with their feet $4 \mathrm{~cm}$ apart. The arms were held alongside the body. Each recording lasted 30 seconds. The first recording was done with the patient with eyes open (EO); the second, with the eyes closed (EC); the third, with tandem stance with eyes closed (TAN); and the last, with the EO producing words starting with "K" 
(COG). The cognitive performance of participants was not evaluated during the cognitive task. In TAN, one foot is in front of the other, and the arms lifted up and extended in front of the body. Sway path, anterior-posterior (A-P) sway, lateral sway, sway area, as well as the velocity of all of these sway values (sway path/time, A-P sway/time, lateral sway/ time, sway area/time) were recorded. Definition of SPG parameters are shown in Table 1.

\section{Statistical analysis}

All analyses were performed using the SPSS ${ }^{\circ}$ for Windows software package (Version 20.0. Armonk, NY: IBM Corp.). Continuous variables were summarized as means and standard deviation. The normality of distribution for continuous variables was confirmed with the Shapiro Wilk test. For variables with a normal distribution, a parametric test, such as Student's t-test was used. Variables without a normal distribution were evaluated using the nonparametric Mann-Whitney U test. For comparison of two related (paired) continuous variables, paired samples Student's t-test for variables with a normal distribution or Wilcoxon Signed Rank test for variables without a normal distribution was used. Pearson's coefficient was used in the correlation analysis of numeric variables with a normal distribution, and Spearman's correlation coefficient was used for the analysis of numerical variables without normal distribution. The hypothesis tests were conducted to verify the

Table 1. Definiton of the static posturography parameters.

\begin{tabular}{|c|c|}
\hline Parameter & Definition \\
\hline Sway path & $\begin{array}{l}\text { Sum of the movements of the } \\
\text { centre of pressure during the whole } \\
\text { examination time }(\mathrm{cm})\end{array}$ \\
\hline Way velocity & $\begin{array}{l}\text { Average speed of the movement } \\
\text { of the centre of pressure }(\mathrm{cm} / \mathrm{sec} \text { ) } \\
\text { (way velocity) }\end{array}$ \\
\hline Sway Area (SA) & $\begin{array}{l}\text { Calculation of the sway area } \\
\text { acording to the formula of Diener/ } \\
\text { Dichgans/Bacher }\left(\mathrm{cm}^{2}\right), x i \text { and y iare } \\
\text { the coordinates at the time i of the } \\
\text { centre of pressure) } \\
\qquad S A=1 / 2 \sum_{i=1}^{n-1}\left|x_{i+1} y_{i+1} x_{i}\right|\end{array}$ \\
\hline SA velocity & $\begin{array}{c}\text { Area divided by time }\left(\mathrm{cm}^{2} / \mathrm{sec}\right) \text { (Sway } \\
\text { area velocity) }\end{array}$ \\
\hline Anterior-posterior (A-P) & $\begin{array}{l}\text { Sum of the y components of the } \\
\text { movement vectors }(\mathrm{cm} / \mathrm{s}) \\
\qquad \Sigma\left|y_{i+1}-y_{i}\right|\end{array}$ \\
\hline A-P sway velocity & $\begin{array}{c}\text { Quotient of Antero-Posterior ant } \\
\text { time }(\mathrm{cm} / \mathrm{s}) \text { (Anterior-posterior sway } \\
\text { velocity) }\end{array}$ \\
\hline Lateral & $\begin{array}{l}\text { Sum of the } x \text { components of the } \\
\text { movement vectors }(\mathrm{cm}) \\
\qquad \sum\left|y_{i+1}-y_{i}\right|\end{array}$ \\
\hline Lateral sway velocity & $\begin{array}{l}\text { Quotient of lateral and time }(\mathrm{cm} / \mathrm{s}) \\
\text { (lateral sway velocity) }\end{array}$ \\
\hline
\end{tabular}

nullity of the correlation coefficients. The statistical level of significance for all tests was considered as 0.05 .

\section{RESULTS}

\section{Participants}

Demographic features of the subjects are shown in Table 2. The most common CD type was torticollis and was present in $83.3 \%(\mathrm{n}=20)$ of patients. Dystonic head tremor was present in $37.5 \%(n=9)$ of them (Table 3).

\section{Posturographic parameters}

With the baseline EO condition, only A-P sway and sway path velocity were significantly higher in $\mathrm{CD}$ than in controls. EC did not have any effect on PS, whereas TAN affected almost all sway parameters in CD significantly (Table 4). The effect of cognitive dual task was more prominent in the sway velocities (Table 4).

BoNT treatment did not lead to a significant reduction in the sway parameters. Only a few parameters get better after the injection. A-P sway in EO, lateral sway and sway path in TAN and lateral sway velocity in cognitive dual tasking improved significantly after BoNT injection (Table 5). Age, disease duration and TWSTRS score did not correlate with any posturographic parameters.

Table 2. Demographic and clinical characteristics of participants.

\begin{tabular}{lcc} 
& \multicolumn{1}{c}{$\begin{array}{c}\text { CD patients } \\
(\mathrm{n}=24)\end{array}$} & $\begin{array}{c}\text { Controls } \\
(\mathrm{n}=23)\end{array}$ \\
\hline Age (years) & $48 \pm 14.5$ (range 20-72) & $49.3 \pm 13.8$ (range 22-72) \\
Gender (F/M) & $14 / 10$ & $14 / 9$ \\
$\begin{array}{l}\text { Disease } \\
\text { duration (years) }\end{array}$ & $13.1 \pm 9.9$ (range 1-32) & - \\
TWSTRS score & $12.3 \pm 6.1$ (range 5-27) & - \\
\hline
\end{tabular}

CD: cervical dystonia; F: Female; M: Male; TWSTRS: Toronto Western Spazmodic torticollis scale

Table 3. Types of cervical dystonia.

\begin{tabular}{lcccc} 
& $\mathrm{n}$ & $\%$ & $\begin{array}{c}\text { DHT } \\
\mathrm{n}(\%)\end{array}$ & TWSTRS \\
\hline Pure Type & 14 & 58.3 & $7(29.4)$ & 11.7 \\
$\quad$ Torticollis & 10 & 41.6 & & \\
Laterocollis & 3 & 12.5 & & \\
Anterocollis & 1 & 4.2 & & \\
Mixed Type & 10 & 41.6 & $2(8.3)$ & 21.3 \\
Torticollis-Laterocollis & 3 & 12.5 & & \\
Torticollis-Retrocollis & 4 & 16.6 & & \\
Torticollis-Anterocollis & 2 & 8.3 & & \\
Torticollis-Laterocollis- & 1 & 4.2 & & \\
Anterocollis & & &
\end{tabular}

DHT: dystonic head tremor; TWSTRS: Toronto Western Spasmodic Torticollis Scale 


\section{DISCUSSION}

This is the first study to investigate PS in patients with $\mathrm{CD}$ under cognitive dual task condition. One of the results of our study is that postural control is impaired in patients with

Table 4. Comparison of mean postural sways and velocities between patients and controls.

\begin{tabular}{|c|c|c|c|}
\hline $\begin{array}{l}\text { Postural sways and } \\
\text { velocities }\end{array}$ & $\begin{array}{c}\text { Cervical } \\
\text { Dystonia } \\
\text { (mean } \pm S D)\end{array}$ & $\begin{array}{c}\text { Control } \\
(\text { mean } \pm S D)\end{array}$ & $p$-value \\
\hline \multicolumn{4}{|l|}{ EO } \\
\hline A-P sway $(\mathrm{cm})$ & $28.2 \pm 11.7$ & $22.3 \pm 6.4$ & 0.039 \\
\hline $\mathrm{LS}(\mathrm{cm})$ & $21.5 \pm 11.5$ & $19 \pm 5.7$ & 0.351 \\
\hline $\mathrm{SP}(\mathrm{cm})$ & $40.3 \pm 17.0$ & $33.5 \pm 8.8$ & 0.095 \\
\hline $\mathrm{SA}\left(\mathrm{cm}^{2}\right)$ & $6.6 \pm 6.2$ & $4.2 \pm 2$ & 0.089 \\
\hline A-P sway velocity $(\mathrm{cm} / \mathrm{s})$ & $0.5 \pm 0.5$ & $0.7 \pm 0.4$ & 0.763 \\
\hline LS velocity (cm/s) & $0.8 \pm 0.5$ & $0.9 \pm 0.2$ & 0.214 \\
\hline SPvelocity $(\mathrm{cm} / \mathrm{s})$ & $1.4 \pm 0.6$ & $1.1 \pm 0.3$ & 0.038 \\
\hline SA velocity $\left(\mathrm{cm}^{2} / \mathrm{s}\right)$ & $0.008 \pm 0.2$ & $0.001 \pm 0.001$ & 0.162 \\
\hline \multicolumn{4}{|l|}{ EC } \\
\hline A-P sway $(\mathrm{cm})$ & $43.8 \pm 31.2$ & $35.5 \pm 23$ & 0.090 \\
\hline $\mathrm{LS}(\mathrm{cm})$ & $25.5 \pm 12.5$ & $21.5 \pm 8.4$ & 0.388 \\
\hline $\mathrm{SP}(\mathrm{cm})$ & $56.6 \pm 34.3$ & $46.6 \pm 24.9$ & 0.166 \\
\hline $\mathrm{SA}\left(\mathrm{cm}^{2}\right)$ & $12.2 \pm 13.4$ & $8 \pm 8.5$ & 0.126 \\
\hline A-P sway velocity $(\mathrm{cm} / \mathrm{s})$ & $1 \pm 0.5$ & $0.7 \pm 0.5$ & 0.089 \\
\hline LS velocity (cm/s) & $1.5 \pm 1.1$ & $1.2 \pm 0.7$ & 0.155 \\
\hline SP velocity $(\mathrm{cm} / \mathrm{s})$ & $1.8 \pm 1.1$ & $1.5 \pm 0.8$ & 0.239 \\
\hline SA velocity $\left(\mathrm{cm}^{2} / \mathrm{s}\right)$ & $0.2 \pm 0.5$ & $0.09 \pm 0.2$ & 0.250 \\
\hline \multicolumn{4}{|l|}{ TAN } \\
\hline A-P sway $(\mathrm{cm})$ & $97.1 \pm 67.6$ & $35.4 \pm 19.7$ & $<0.001$ \\
\hline $\mathrm{S}(\mathrm{cm})$ & $80.7 \pm 44.2$ & $29.7 \pm 24.7$ & $<0.001$ \\
\hline $\mathrm{SP}(\mathrm{cm})$ & $140 \pm 86.2$ & $52.5 \pm 33.7$ & $<0.001$ \\
\hline $\mathrm{SA}\left(\mathrm{cm}^{2}\right)$ & $54.1 \pm 60.1$ & $11.3 \pm 15.5$ & $<0.001$ \\
\hline A-P sway velocity $(\mathrm{cm} / \mathrm{s})$ & $3.4 \pm 2.5$ & $2 \pm 0.7$ & $<0.001$ \\
\hline LS velocity (cm/s) & $3.3 \pm 2.2$ & $1 \pm 0.9$ & 0.086 \\
\hline SP velocity $(\mathrm{cm} / \mathrm{s})$ & $4.6 \pm 1.8$ & $2.3 \pm 1.1$ & $<0.001$ \\
\hline $\mathrm{SA}$ velocity $\left(\mathrm{cm}^{2} / \mathrm{s}\right)$ & $7.5 \pm 9.1$ & $1.6 \pm 1.8$ & $<0.001$ \\
\hline \multicolumn{4}{|l|}{ COG } \\
\hline A-P sway $(\mathrm{cm})$ & $36.1 \pm 19.1$ & $29.5 \pm 10.3$ & 0.163 \\
\hline LS (cm) & $25.2 \pm 15.3$ & $19.2 \pm 6.1$ & 0.253 \\
\hline $\mathrm{SP}(\mathrm{cm})$ & $49.2 \pm 25.6$ & $39.7 \pm 12.1$ & 0.221 \\
\hline $\mathrm{SA}\left(\mathrm{cm}^{2}\right)$ & $11.1 \pm 15.6$ & $6.3 \pm 5$ & 0.234 \\
\hline A-P sway velocity $(\mathrm{cm} / \mathrm{s})$ & $0.8 \pm 0.6$ & $0.8 \pm 0.3$ & 0.933 \\
\hline LS velocity (cm/s) & $1.2 \pm 0.6$ & $0.2 \pm 0.5$ & $<0.001$ \\
\hline SP velocity $(\mathrm{cm} / \mathrm{s})$ & $1.6 \pm 0.9$ & $0.7 \pm 0.7$ & $<0.001$ \\
\hline SA velocity $\left(\mathrm{cm}^{2} / \mathrm{s}\right)$ & $0.4 \pm 0.6$ & $0.2 \pm 0.5$ & $<0.001$ \\
\hline
\end{tabular}

A-P: antero-posterior; COG: cognitive task; EO: eyes open; EC: eyes closed; LS:lateral sway; SA:sway area; SP sway path; SD: standard deviation; TAN: tandem stance
CD compared to the healthy controls under baseline EO condition. EC condition does not have any effect, whereas TAN, which is the harder postural task, affected PS of CD patients more prominently than the other conditions. Cognitive task

Table 5. Pairwise comparisons of mean postural sways, velocities and TWSTRS scores before and after BoNT.

\begin{tabular}{|c|c|c|c|}
\hline $\begin{array}{l}\text { Posturographic } \\
\text { parameters } \\
\text { and TWSTRS }\end{array}$ & $\begin{array}{c}\text { Before } \\
\text { BoNT } \\
\text { (mean } \pm \text { SD) }\end{array}$ & $\begin{array}{l}\text { After BoNT } \\
(\text { mean } \pm S D)\end{array}$ & $p$-value \\
\hline TWSTRS score & $12.3 \pm 6.1$ & $8.8 \pm 4.6$ & $<0.001$ \\
\hline \multicolumn{4}{|l|}{ EO } \\
\hline A-P sway $(\mathrm{cm})$ & $28.2 \pm 11.7$ & $24.9 \pm 7.1$ & 0.012 \\
\hline LS (cm) & $21.5 \pm 11.5$ & $20.1 \pm 8.2$ & 0.169 \\
\hline $\mathrm{SP}(\mathrm{cm})$ & $40.3 \pm 17$ & $36.7 \pm 11$ & 0.071 \\
\hline $\mathrm{SA}\left(\mathrm{cm}^{2}\right)$ & $6.6 \pm 6.2$ & $5.2 \pm 3.1$ & 0.146 \\
\hline A-P sway velocity $(\mathrm{cm} / \mathrm{s})$ & $0.5 \pm 0.5$ & $1 \pm 0.001$ & 0.987 \\
\hline LS velocity (cm/s) & $0.8 \pm 0.5$ & $0.5 \pm 0.5$ & 0.426 \\
\hline SP velocity(cm/s) & $1.4 \pm 0.6$ & $1.2 \pm 0.4$ & 0.135 \\
\hline SA velocity $\left(\mathrm{cm}^{2} / \mathrm{s}\right)$ & $0.008 \pm 0.2$ & $0.01 \pm 0.01$ & 0.162 \\
\hline
\end{tabular}
EC

$\begin{array}{lccc}\text { A-P sway }(\mathrm{cm}) & 43.8 \pm 31.2 & 39.1 \pm 16.8 & 0.153 \\ \text { LS }(\mathrm{cm}) & 25.5 \pm 12.5 & 23.7 \pm 10.5 & 0.193 \\ \text { SP }(\mathrm{cm}) & 56.6 \pm 34.3 & 51.3 \pm 20.1 & 0.149 \\ \text { SA }\left(\mathrm{cm}^{2}\right) & 12.2 \pm 13.4 & 10.9 \pm 9.2 & 0.810 \\ \text { A-P sway velocity }(\mathrm{cm} / \mathrm{s}) & 1 \pm 0.5 & 1.3 \pm 0.5 & 0.059 \\ \text { LS velocity }(\mathrm{cm} / \mathrm{s}) & 1.5 \pm 1.1 & 0.7 \pm 0.5 & 0.257 \\ \text { SP velocity }(\mathrm{cm} / \mathrm{s}) & 1.8 \pm 1.1 & 1.7 \pm 0.6 & 0.439 \\ \text { SA velocity }\left(\mathrm{cm}^{2} / \mathrm{s}\right) & 0.2 \pm 0.5 & 0.1 \pm 0.3 & 0.083\end{array}$

\begin{tabular}{|c|c|c|c|}
\hline \multicolumn{4}{|l|}{ TAN } \\
\hline A-P sway (cm) & $97.1 \pm 67.6$ & $96.1 \pm 60.7$ & 0.225 \\
\hline LS (cm) & $80.7 \pm 44.2$ & $76.7 \pm 40.4$ & 0.038 \\
\hline $\mathrm{SP}(\mathrm{cm})$ & $140 \pm 86.2$ & $136.9 \pm 78.4$ & 0.048 \\
\hline $\mathrm{SA}\left(\mathrm{cm}^{2}\right)$ & $54.1 \pm .60 .1$ & $53.8 \pm 62.2$ & 0.478 \\
\hline A-P sway velocity $(\mathrm{cm} / \mathrm{s})$ & $3.4 \pm 2.5$ & $3.1 \pm 2$ & 0.314 \\
\hline LS velocity (cm/s) & $3.3 \pm 2.2$ & $2.6 \pm 1.3$ & 0.289 \\
\hline SP velocity(cm/s) & $4.6 \pm 1.8$ & $4.5 \pm 2.6$ & 0.309 \\
\hline SA velocity $\left(\mathrm{cm}^{2} / \mathrm{s}\right)$ & $7.5 \pm 9.1$ & $6.9 \pm 2.2$ & 0.582 \\
\hline \multicolumn{4}{|l|}{ COG } \\
\hline A-P sway $(\mathrm{cm})$ & $36.1 \pm 19.1$ & $35.1 \pm 16.5$ & 0.396 \\
\hline LS (cm) & $25.2 \pm 15.3$ & $24.2 \pm 15$ & 0.073 \\
\hline $\mathrm{SP}(\mathrm{cm})$ & $49.2 \pm 25.6$ & $48.1 \pm 23.9$ & 0.278 \\
\hline $\mathrm{SA}\left(\mathrm{cm}^{2}\right)$ & $11.1 \pm 15.6$ & $12.9 \pm 16$ & 0.276 \\
\hline A-P sway velocity $(\mathrm{cm} / \mathrm{s})$ & $0.8 \pm 0.6$ & $0.8 \pm 0.4$ & 0.655 \\
\hline LS velocity (cm/s) & $1.2 \pm 0.6$ & $0.7 \pm 0.6$ & 0.046 \\
\hline SP velocity $(\mathrm{cm} / \mathrm{s})$ & $1.6 \pm 0.9$ & $1.6 \pm 0.9$ & 0.987 \\
\hline SA velocity $\left(\mathrm{cm}^{2} / \mathrm{s}\right)$ & $0.4 \pm 0.6$ & $0.2 \pm 0.5$ & 0.164 \\
\hline
\end{tabular}

A-P: antero-posterior; BoNT: botulinum toxin; COG: cognitive task; EO: eyes open; EC: eyes closed; LS:lateral sway; SA:sway area; SD: standard deviation; SP : sway path;TWSTRS:Toronto-Western Spazmodic Torticollis Rating Scale 
affected the sway velocities in patients significantly. There are a few studies in literature investigating PS in CD, and the results are controversial ${ }^{7,17,19,20,22}$. Lekhel et al. ${ }^{19}$ and Moreau et al. ${ }^{20}$ reported that there was no significant difference in lateral and A-P sways between CD patients and controls. In contrast to these studies, Bove et al. ${ }^{7}$ and Wöber et al. ${ }^{26}$ reported significant increase in postural sway parameters such as sway path, sway area, medio-lateral and A-P sway values in CD compared to the controls. Barr et al. reported that CD patients swayed more than controls, had poor postural control and walked more slowly than controls ${ }^{18}$. De Pauw et al. reported increased postural sway and impaired PS in patients with $\mathrm{CD}^{5}$. Differences in the study protocols including patient selection and variations in the posturographic protocols may explain these discrepancies.

The normal balance function provides the ability to maintain the erect posture of the body in motion or stable condition. For this to happen, precise data from vestibular, visual, body sensory systems should be taken, reconciled, unnecessary information should be eliminated and selected actions should be made appropriate. A robust neurological and skeletal system is required for all this to occur. However, our results suggest that visual input may not have much effect on PS in these patients. Therefore, we assume that visual input probably has the least effect on postural balance in patients with $\mathrm{CD}$. As suggested by some earlier studies, proprioceptive and sensorimotor integration are probably more important components of PS in patients with $\mathrm{CD}^{7,8,9,10,11}$.

Up to date, there are no studies evaluating the effect of dual-tasking on postural control in patients with CD. An important finding of the present study is the effect of cognitive dual-tasking in patients with $\mathrm{CD}$. We found that cognitive task impaired PS in these patients more than controls. The effect was more prominent on the sway velocities in posturographic analyses. Some theories have been put forward to explain the difficulties in performing dual tasks. The most prevalent are capacity sharing, bottleneck (task switching), and cross talk $k^{27}$. According to capacity sharing theory, which is the most widely accepted, performing two tasks at the same time decreases the performance of each task due to the division of capacity for tasks ${ }^{27}$. In bottleneck (task-switching) model, parallel processing may be impossible for some mental operations ${ }^{27}$. Some operations may simply require a single mechanism to be dedicated to them for some period of time. When two tasks need the mechanism simultaneously, a bottleneck occurs, and one or both tasks will be delayed or otherwise impaired. The crosstalk model is being used to refer to conditions in which informational code overlaps across tasks $^{27}$. Taleli et al. ${ }^{28}$ suggested that differential cortical activation within the higher neural centers can affect task prioritization, further allowing increased conscious attention while carrying out cognitive or motor tasks. Therefore, we can say that attention is an important variable to maintain PS under dual task conditions in patients with $\mathrm{CD}$ and an adequate attention function is required to provide postural control and balance in such patients under dual task conditions.

During dual task assessment, the two tasks performed simultaneously in a dual task paradigm can be two cognitive, two motor, or a motor and a cognitive task ${ }^{29}$. Dual task costs, that is, decline in performance of either or both tasks can be due to age or illness-related conditions ${ }^{30,31}$. Hence, patients with $\mathrm{CD}$ may experience reduction in performance when performing two activities that require attention at the same time, such as finding words starting with $\mathrm{K}$ and maintaining PS, leading to dual task costs ${ }^{32}$. They may have a tendency to prioritize the motor task, which is PS, in the presence of a cognitive or another challenging motor task $\mathrm{k}^{33,34,35,36,37}$.

In the literature, there are contradictory results on the effect of BoNT on PS in CD patients. In our study, BoNT injection had little effect on PS of CD patients; in cognitive task, only one sway velocity (lateral sway velocity), and in TAN stance two sway parameters (lateral sway and sway path) improved. Wöber et al. ${ }^{26}$ reported that the whole-body postural control was impaired in more than $75 \%$ of idiopathic CD patients and had improved with local injections with BoNT-A. On the other hand, De Pauw et al. ${ }^{38}$ reported that BoNT injection had little utility on cervical sensorimotor control, postural control, and visual vertical perception. In our study, as seen in the improvement of TWSTRS scores, BoNT is an effective treatment for CD, but it did not have much effect on PS of these patients. It affects the contraction of the muscles, leading to a better posture of the head and neck, but this peripherally and improved posture probably does not have any retrograde effects on central mechanisms which control the PS of patients with CD. In other words, the PS of CD is the result of central mechanisms. Controlling the peripheral mechanism, such as improving the faulty contraction of neck muscles, probably does not provide additional help in the maintenance of PS. More data in larger series is needed on this subject to fully understand the effect of BoNT on PS in CD.

The present study has limitations. The absence of BoNTnaive patient group is one of them. We included only the patients who were already under treatment. The number of patients with dystonic head tremor was low. Therefore, we were unable to analyze the effect of dystonic head tremor on these parameters in relation to dual-tasking. Different types of CD may have different impacts on PS. Nonetheless, the number of patients are not enough to evaluate the effect of each type of $\mathrm{CD}$. For standardization, we used the same order of tests in the posturographic analysis in every subject. This might have had some practice effects.

In conclusion, PS is impaired in patients with CD. Vision may not be as essential for PS in these patients like proprioceptive and sensorimotor integration are. Cognitive dual task disturbes PS in CD probably due to divided attention and task prioritization. BoNT injection does not seem to have much effect on PS in patients with CD. More comprehensive studies of posturography with complex motor or cognitive tasks may provide further information on this subject. 
1. Defazio G, Jankovic C, Giel JL, Papapetropoulos S. Descriptive epidemiology of cervical dystonia. Tremor Other Hyperkinet Mov (N Y). 2013;3:tre-03-193-4374-2. https://doi.org/10.7916/D80C4TGJ

2. Albanese A, Bhatia K, Bressman SB, Delong MR, Fahn S, Fung VS, et al. Phenomenology and classification of dystonia: a consensus update. Mov Disord. 2013 Jun;28(7):863-73. https://doi.org/10.1002/ mds. 25475

3. Costa J, Espírito-Santo C, Borges A, Ferreira JJ, Coelho M, Moore P, Sampaio C. Botulinum toxin type A therapy for cervical dystonia. Cochrane Database Syst Rev. 2005;1:CD003633. http://dx.doi. org/10.1002/14651858.CD003633.pub2

4. Marsh WA, Monroe DM, Brin MF, Gallagher CJ. Systematic review and meta-analysis of the duration of clinical effect of onabotulinumtoxinA in cervical dystonia. BMC Neurol. 2014 Apr;14:91. https://doi.org/10.1186/1471-2377-14-91

5. De Pauw J, Mercelis R, Hallemans A, Van Gils G, Truijen S, Cras P, et al. Postural control and the relation with cervical sensorimotor control in patients with idiopathic adult-onset cervical dystonia. Exp Brain Res. 2018 Mar;236(3):803-11. https://doi.org/10.1007/ s00221-018-5174-X

6. Abbruzzese G, Marchese R, Buccolieri A, Gasparetto B, Trompetto C. Abnormalities of sensorimotor integration in focal dystonia: a transcranial magnetic stimulation study. Brain. 2001 Mar;124(Pt 3):537-45. https://doi.org/10.1093/brain/124.3.537

7. Bove M, Brichetto G, Abbruzzese G, Marchese R, Schieppati M. Postural responses to continuous unilateral neck muscle vibration in standing patients with cervical dystonia. Mov Disord. 2007 Mar;22(4):498-503. https://doi.org/10.1002/mds.21357

8. De Pauw J, Mercelis R, Hallemans A, Michiels S, Truijen S, Cras P, et al. Cervical sensorimotor control in idiopathic cervical dystonia: a cross-sectional study. Brain Behav. 2017;7(9):e00735. https://doi. org/10.1002/brb3.735

9. Vuillerme N, Pinsault N. Experimental neck muscle pain impairs standing balance in humans. Exp Brain Res. 2009 Feb;192(4):723-9. https://doi.org/10.1007/s00221-008-1639-7

10. Treleaven J, Jull G, LowChoy N. The relationship of cervical joint position error to balance and eye movement disturbances in persistent whiplash. Man Ther. 2006 May;11(2):99-106. https://doi. org/10.1016/j.math.2005.04.003

11. Field S, Treleaven J, Jull G. Standing balance: a comparison between idiopathic and whiplash-induced neck pain. Man Ther. 2008 Jun;13(3):183-91. https://doi.org/10.1016/j.math.2006.12.005

12. Münchau A, Bronstein AM. Role of the vestibular system in the pathophysiology of spasmodic torticollis. J Neurol Neurosurg Psychiatry. 2001 Sep;71(3):285-8. https://doi.org/10.1136/ jnnp.71.3.285

13. Bronstein AM, Rudge P. Vestibular involvement in spasmodic torticollis. J Neurol Neurosurg Psychiatry. 1986 Mar;49(3):290-5. https://doi.org/10.1136/jnnp.49.3.290

14. Stejskal L, Tománek Z. Postural laterality in torticollis and torsion dystonia.J Neurol Neurosurg Psychiatry. 1981 Nov;44(11):1029-34. https://doi.org/10.1136/jnnp.44.11.1029

15. Stell R, Bronstein AM, Marsden CD. Vestibulo-ocular abnormalities in spasmodic torticollis before and after botulinum toxin injections. J Neurol Neurosurg Psychiatry. 1989 Jan;52(1):57-62. https://doi. org/10.1136/jnnp.52.1.57

16. Huygen PL, Verhagen WI, Van Hoof JJ, Horstink MW. Vestibular hyperreactivity in patients with idiopathic spasmodic torticollis. J Neurol Neurosurg Psychiatry. 1989 Jun;52(6):782-5. https://doi. org/10.1136/jnnp.52.6.782

17. Diamond SG, Markham CH, Baloh RW. Ocular counterrolling abnormalities in spasmodic torticollis. Arch Neurol.
1988 Feb;45(2):164-9. https://doi.org/10.1001/ archneur.1988.00520260050019

18. Barr C, Barnard R, Edwards L, Lennon S, Bradnam L. Impairments of balance, stepping reactions and gait in people with cervical dystonia. Gait Posture. 2017 Jun;55:55-61. https://doi.org/10.1016/j. gaitpost.2017.04.004

19. Lekhel H, Popov K, Anastasopoulos D, Bronstein A, Bhatia Kailash, Marsden CD, et al. Postural responses to vibration of neck muscles in patients with idiopathic torticollis. Brain. 1997;120(Pt 4):583-91. https://doi.org/10.1093/brain/120.4.583

20. Moreau MS, Cauquil SA, Costes Salon M. Static and dynamic balance function in spasmodic torticollis. Mov Disord. 1999 Jan;14(1):8794. https://doi.org/10.1002/1531-8257(199901)14:1\%3C87::aidmds1015\%3E3.0.co;2-c

21. Tsang WW, Chan VW, Wong HH, Yip TW, Lu X. The effect of performing a dual-task on postural control and selective attention of older adults when stepping backward. J Phys Ther Sci. 2016;28(10):2806-11. https://doi.org/10.1589/jpts.28.2806

22. Dault MC, Frank JS, Allard F. Influence of a visuo-spatial, verbal and central executive working memory task on postural control. Gait Posture. 2001 Oct;14(2):110-6. https://doi.org/10.1016/s09666362(01)00113-8

23. Müller J, Ebersbach G, Wissel J, Poewe W. Dynamic balance function in phasic cervical dystonia following Botulinum Mov Disord. 2001 Sep;16(5):934-7. https://doi.org/10.1002/mds.1164

24. Consky ES, Basinki A, Belle L, Ranawaya R, Lang AE. The Toronto Western Spasmodic Torticollis Rating Scale (TWSTRS): assessment of validity and inter-rater reliability. Neurology. 1990;40(Suppl 1):S445

25. Odergren T, Hjaltason H, Kaakkola S, Solders G, Hanko J, Fehling C, et al. A double blind, randomised, parallel group study to investigate the dose equivalence of dysport and botox in the treatment of cervical dystonia.J Neurol Neurosurg Psychiatry. 1998 Jan;64(1):6-12. https://doi.org/10.1136/jnnp.64.1.6

26. Wöber E, Schnider P, Steinhoff N, Trattnig S, Zebenholzer K, Auff E. Posturographic findings in patients with idiopathic cervical dystonia before and after local injections with botulinum toxin. Eur Neurol. 1999;41(4):194-200. https://doi.org/10.1159/000008050

27. Pashler H. Dual-task interference in simple tasks: data and theory. Psychol Bull. 1994 Sep;116(2):220-44. https://doi.org/10.1037/00332909.116.2.220

28. Talelli P, Ewas A, Waddingham W, Rothwell J, Ward N. Neural correlates of age-related changes in cortical neurophysiology. Neuroimage. 2008 May;40(4):1772-81. https://doi.org/10.1016/j. neuroimage.2008.01.039

29. Saxena S, Cinar E, Majnemer A, Gagnon I. Does dual tasking ability change with age across childhood and adolescence? A systematic scoping review. Int J Dev Neurosci. 2017 May;58:35-49. https://doi. org/10.1016/j.ijdevneu.2017.01.012

30. Bekkers EMJ, Dockx K, Devan S, Van Rossom S, Verschueren SMP, Bloem BR, et al. The Impact of dual-tasking on postural stability in people with Parkinson's disease with and without freezing of gait. Neurorehabil Neural Repair. 2018 Feb;32(2):166-74. https://doi. org/10.1177/1545968318761121

31. Liu YC, Yang YR, Tsai YA, Wang RY. Cognitive and motor dual task gait training improve dual task gait performance after stroke - A randomized controlled pilot trial. Sci Rep. 2017;7(1):4070. https://doi. org/10.1038/s41598-017-04165-y

32. Krampe RT, Schaefer S, Lindenberger U, Baltes PB. Lifespan changes in multi-tasking: concurrent walking and memory search in children, young, and older adults. Gait Posture. 2011 Mar;33(3):401-5. https:// doi.org/10.1016/j.gaitpost.2010.12.012 
33. Brown LA, Sleik RJ, Polych MA, Gage WH. Is the prioritization of postural control altered in conditions of postural threat in younger and older adults? J Gerontol A Biol Sci Med Sci. 2002 Dec;57(12):M785-92. https://doi.org/10.1093/gerona/57.12.m785

34. Doumas M, Rapp M, Krampe RT. Working memory and postural control: adult age differences in potential for improvement, taskpriority and dual-tasking. J Gerontol B Psychol Sci Soc Sci. 2009 Mar;64B(2):193-201. https://doi.org/10.1093/geronb/gbp009

35. Doumas M, Smolders C, Krampe RT. Task prioritization in aging: effects of sensory information on concurrent posture and memory performance. Exp Brain Res. 2008 May;187(2):275-81. https://doi. org/10.1007/s00221-008-1302-3
36. Li KZH, Lindenberger U, Freund AM, Baltes PB. Walking while memorizing: age-related differences in compensatory behavior. Psychol Sci. 2001 May;12(3):230-7. https://doi.org/10.1111/14679280.00341

37. Rapp M, Krampe RT, Baltes PB. Adaptive task prioritization in aging: selective resource allocation to postural control is preserved in Alzheimer disease. Am J Geriatr Psychiatry. 2006 Jan;14(1):52-61. https://doi.org/10.1097/01.JGP.0000192490.43179.e7

38. De Pauw J, Cras P, Truijen S, Mercelis R, Michiels S, Saeys W, et al. The effect of a single botulinum toxin treatment on somatosensory processing in idiopathic isolated cervical dystonia: an observational study.J Neurol. 2018 Nov;265(11):2672-2683. https://doi. org/10.1007/s00415-018-9045-y 